\title{
Alexithymia, impulsiveness, and psychopathology in nonsuicidal self-injured adolescents
}

\author{
This article was published in the following Dove Press journal: \\ Neuropsychiatric Disease and Treatment \\ 12 September 2016 \\ Number of times this article has been viewed
}

\author{
Michela Gatta' \\ Francesco Dal Santo' \\ Alessio Rago' \\ Andrea Spoto ${ }^{2}$ \\ Pier Antonio Battistella' \\ 'Childhood Adolescence Family \\ Unit, Ulss 16 - Padua University, \\ ${ }^{2}$ Department of General Psychology, \\ Padua University, Padova, Italy
}

Introduction: Nonsuicidal self-injury (NSSI) is a multifaceted phenomenon and a major health issue among adolescents. A better understanding of self-injury comorbidities is crucial to improve our ability to assess, treat, and prevent NSSI.

Purpose: This study aimed at analyzing some of the psychobehavioral correlates of NSSI: psychological problems, alexithymia, impulsiveness, and sociorelational aspects.

Patients and methods: This was a case-control study. The clinical sample $(n=33)$ included adolescents attending our unit for NSSI and other issues; the controls $(n=79)$ were highschool students. Data were collected using six questionnaires: Youth Self-Report, Barratt's Impulsiveness Scale, Toronto Alexithymia Scale, Children's Depression Inventory, Symptom Checklist-90-R, and Child Behavior Checklist.

Results: Cases scored significantly higher in all questionnaires. Habitual self-injurers scored higher on impulsiveness and alexithymia. The gesture's repetition seems relevant to the global clinical picture: habitual self-injurers appear more likely to seek help from the sociosanitary services. We found a difference between the self-injurers' and their parents' awareness of the disorder.

Conclusion: Habitual self-injurers show signs of having difficulty with assessing the consequences of their actions (nonplanning impulsiveness) and the inability to manage their feelings. Given the significantly higher scores found for cases than for controls on all the psychopathological scales, NSSI can be seen as a cross-category psychiatric disorder, supporting the Diagnostic and Statistical Manual of Mental Disorders decision to include it as a pathological entity in its own right.

Keywords: NSSI, self-cutting, psychiatric comorbidity, impulsivity, self-report, self-harm

\section{Introduction}

\section{Background}

Nonsuicidal self-injury (NSSI) refers to the socially unacceptable, intentional, and direct injuring of one's own body tissue without suicidal intent. ${ }^{1}$ Various terms have been used to describe and define self-injury and NSSI has recently been included in Section 3 of the latest Diagnostic and Statistical Manual of Mental Disorders (DSM-V) as a separate diagnostic entity. ${ }^{2}$

It is a relatively common, multifaceted phenomenon among adolescents, representing a major health issue in this age group. A recent meta-analysis reported an adjusted lifetime pooled prevalence of NSSI for adolescents of $17.2 \%,{ }^{3}$ a figure very similar to the findings of previous studies. ${ }^{4}$ It has been estimated that only about one in eight self-harming adolescents in the community go to hospital..$^{5}$ The methods used to self-inflict injuries typically involve cutting or scratching the skin, though other methods are used too. ${ }^{6}$ Cutting is generally done on the arms, but self-injurers
Correspondence: Michela Gatta Childhood Adolescence Family Unit, ULSS 16, Via Colli 4

Padova 35I43, Italy

Tel +390498217690

Fax +390498217 708

Email michela.gatta@unipd.it
Neuropsychiatric Disease and Treatment 2016:12 2307-2317 Dovepress in 0 http://dx.doi.org/10.2147/NDT.S106433 (c) (1) (-) 2016 Gatta et al. This work is published and licensed by Dove Medical Press Limited. The full terms of this license are available at https://www.dovepress.com/terms.php cc) ${ }_{\mathrm{BY}} \mathrm{NC}$ and incorporate the Creative Commons Attribution - Non Commercial (unported, v3.0) License (http://creativecommons.org/licenses/by-nc/3.0/). By accessing the work you hereby accept the Terms. Non-commercial uses of the work are permitted without any further permission from Dove Medical Press Limited, provided the work is properly attributed. For permission for commercial use of this work, please see paragraphs 4.2 and 5 of our Terms (https://www.dovepress.com/terms.php). 
quite often damage other parts of their body as well. ${ }^{7}$ The results of previous studies vary, but most research indicates a preponderance of girls in the clinical population of NSSI cases. ${ }^{8-10}$ In Italy, studies considering nonclinical samples have shown no differences between the sexes, ${ }^{11,12}$ while the opposite was true of clinical samples. ${ }^{13}$

A number of psychological and psychiatric correlates have been found implicated in the onset and/or repetition of NSSI behavior. Nock et al ${ }^{14}$ reported that more than half of the clinical adolescents they studied met the DSM-IV criteria for an internalizing disorder, an externalizing disorder, or a substance-related disorder, with a prevalence rate of psychiatric pathologies estimated to be as high as $87 \%$. In a large community-based sample of 12,068 adolescents from eleven countries, Brunner et $\mathrm{a}^{6}$ found significant associations with symptoms of depression and anxiety in adolescents who engaged in self-harming behavior, and they emphasized that self-injury is strongly indicative of psychological problems that require professional attention. Their results are consistent with previous reports of a significantly higher rate of depressive and anxious symptoms in self-injurers. ${ }^{5,15-19}$ The onset of NSSI behavior in teenagers with depression is mainly attributable to the function of NSSI as a way to seek relief from the depressive symptoms. ${ }^{20}$ The literature generally stresses the broad variety of psychiatric problems seen in teenagers with a history of NSSI. Cluster B personality disorders are often identified, especially in self-cutting adolescent females, and so are eating disorders; approximately one in three adolescents with eating disorders are also selfinjurers, the NSSI frequently coinciding with or following the eating disorder. ${ }^{21,22}$

Aside from the psychiatric diagnoses, psychological traits such as alexithymia and impulsiveness have also been studied in relation to NSSI. Alexithymia is defined as a personality construct featuring a subclinical inability to identify and describe emotions in the self, ${ }^{23}$ and it seems to correlate somehow with the onset of NSSI. Some authors, including Paivio and McCullogh, ${ }^{24}$ have observed this relationship between NSSI and alexithymia and found that more severe clinical presentations of NSSI were associated with higher levels of alexithymia. ${ }^{24-27}$ Findings concerning impulsiveness have been inconsistent: some researchers report that self-injurers perceive themselves as more impulsive in answering self-report questionnaires, ${ }^{18,28-30}$ while other studies using behavioral measures of impulsiveness found no differences vis-à-vis the general population..$^{29,31}$ So the debate on the link between NSSI and impulsiveness remains open.

\section{Aim of this study}

It seems clear that a better understanding of NSSI comorbidities is crucial to improve our ability to assess, treat, and prevent self-injuring behavior, and hence this study, which aimed to conduct a more in-depth analysis of the broad array of psychological and psychiatric correlates of NSSI. We focused particularly on the relationships between NSSI, internalizing and externalizing psychobehavioral problems, specific psychological traits (such as alexithymia and impulsiveness), and sociorelational aspects. We expected clinical subjects to present worse psychopathological symptoms when compared to control cases. Particularly, concerning alexithymic traits, we wanted to demonstrate the importance of the lack in the ability of managing and communicating negative emotions as one of the mechanisms behind NSSI.

In reference to impulsiveness, we hypothesized that greater levels of impulsivity, especially in terms of nonplanning impulsiveness and motor impulsiveness, could be related to an increase in frequency and severity of the disorder.

We think that a better investigation of the role of alexithymia and impulsiveness as NSSI correlates would help, in terms of clinical implications and in planning primary and secondary preventive interventions.

\section{Methods}

\section{Subjects}

Among 88 young people attending a neuropsychiatry unit for children, adolescents, and families (Struttura Complessa Infanzia Adolescenza Famiglia) run by the Italian National Health Service (Unità Locale Socio Sanitaria Padova 16) in Padua (Italy) from January to December 2014, we selected 38 adolescents, consecutively referred to the service between January and October, who presented, during this time, episodes of NSSI. Five of these patients refused to take part in the research, while the remainder of the adolescents and their parents gave written informed consent to the study (our service has a protocol based on the use of standardized forms for obtaining informed consent to the administration of questionnaires and the collection of data for clinical and research purposes, approved by Institution ULSS 16 of Padua). The study was approved by the Research Commitee of the Struttura Complessa Infanzia Adolescenza Famiglia (SCIAF) - Ulss 16 Padova - and the principles outlined in the Declaration of Helsinki were followed. Our final clinical sample thus consisted of 33 adolescents (and their parents), 8 males ( $24.2 \%$ of the sample), and 25 females (75.8\%), aged from 12 to 17 years (mean $=15$ years, standard deviation $[\mathrm{SD}]=1.37)$. 
The control group was recruited from among students attending three local high schools during the academic year 2014-2015. After an informative interview with the headmaster, parents were given a letter describing the research project, providing details of the test methods, and requesting that they sign a form to authorize the adolescent's participation. The questionnaires administered to the controls were the same as those administered to the cases, and were completed anonymously in class during normal school hours, in compliance with current legislation on privacy, and in the presence of an operator from our service. The adolescents were given copies of the Child Behavior Checklist (CBCL) questionnaire to be answered by their parents, asking them to return them to a teacher appointed to collect them within a week. In all, 87 students took part in the study; eight (9.2\%) were subsequently ruled out because they admitted in the questionnaire to having taken some self-harming action, and so the group of controls considered in the statistical analysis amounted to 79 students, 9 males $(11.4 \%$ of the sample) and 70 females (88.6\%), aged from 13 to 18 years (mean $=15.37$ years, $\mathrm{SD}=1.17$ ). The prevalence of females among the controls was consistent with the type of the school (focusing on foreign languages), which was chosen deliberately to mimic the clinical sample.

\section{Procedures}

The questionnaires used in the study (see list in "Study protocol and materials" section) were completed by patients at the time of clinical interviews for their assessment at our unit and, where applicable, by their parents (who were asked to answer the questionnaire jointly). During interviews with patients, we recorded their clinical history, the clinical aspects of their selfharming behavior, their reason for seeking our clinical service, and their diagnosis, formulated according to the international classification of diseases-10 (ICD-10) criteria.

The clinical sample was divided on the grounds of certain characteristics, as outlined below.

A. Reason for accessing our service:

1. patients presenting with NSSI, or who already had experience of said behavior on presentation; this category included 17 adolescents ( $51.5 \%$ of the sample), 3 males and 14 females;

2. patients presenting with problems other than NSSI, who subsequently presented NSSI episodes. This category included 16 patients ( $48.5 \%$ of the sample), with 5 males and 11 females, who were further divided into three subgroups:

I. presenting with affective disorders: six cases
Table I ICD-I0: emotional and/or affective disorders

\begin{tabular}{llll}
\hline ICD-I0 & Males & Females & Total \\
\hline Mood disorders (F30-F39) & 2 & 10 & 12 \\
$\begin{array}{l}\text { Neurotic, stress-related, and } \\
\text { somatoform disorders (F40-F48) }\end{array}$ & 0 & 5 & 5 \\
$\begin{array}{l}\text { Problems related to social } \\
\text { environment (Z60) }\end{array}$ & 0 & 2 & 2 \\
\hline
\end{tabular}

Abbreviation: ICD-10, international classification of diseases-10.

II. presenting with behavioral and conduct disorders: eight cases

III. presenting with disorders of scholastic skills: two cases.

B. ICD-10 diagnosis:

We divided the clinical sample into two main groups, in relationship with the ICD-10 diagnosis, composed as follows:

1. emotional and/or affective disorders: this category included 19 patients $(57.6 \%$ of the clinical population), 2 males and 17 females (Table 1);

2. behavioral and/or personality disorders: this category includes 14 patients $(42.4 \%$ of the clinical population), 6 males and 8 females (Table 2).

C. Frequency of self-injury episodes:

1. occasional self-injury: patients with up to five such episodes/year; this category included 13 patients (39.4\% of the sample), 5 males and 8 females;

2. habitual self-injury: patients with five or more such episodes/year; this category included 20 patients (60.6\% of the sample), 3 males and 17 females.

\section{Study protocol and materials}

A case-control study design was adopted. The cases and controls were administered six questionnaires, five of them the Youth Self-Report (YSR), Barratt's Impulsiveness Scale (BIS-11), the Toronto Alexithymia Scale (TAS-20), the Children's Depression Inventory (CDI), and the Symptom Checklist-90-R (SCL-90-R) - were completed by the adolescents, while the last - the CBCL - was answered by the adolescents' parents (or legal guardians). The scores obtained were first compared between cases and controls. Then comparisons

Table 2 ICD- 10: behavioral and/or personality disorders

\begin{tabular}{llll}
\hline ICD-I0 & Males & Females & Total \\
\hline $\begin{array}{l}\text { Personality and behavioral disorders } \\
\text { (F60-F69) }\end{array}$ & $\mathrm{I}$ & 2 & 3 \\
$\begin{array}{l}\text { Behavioral disorders and of the } \\
\text { emotional sphere with the habitual onset } \\
\text { in infancy and adolescence (F90-F98) }\end{array}$ & 5 & 6 & $\mathrm{II}$ \\
\hline
\end{tabular}

Abbreviation: ICD-10, international classification of diseases-10. 
were drawn between the groups into which the clinical sample was further divided.

The Achenbach questionnaires are among the most commonly used scales for rating juvenile behavior and are used internationally in the clinical setting and in research. ${ }^{32,33}$ We used two questionnaires, one completed by the adolescents (YSR 11-18) and one by their parents (CBCL 6-18). These questionnaires yield two profiles: one for competences (activities, social functioning, and school performance), which tells about how good the adolescent is in sports, hobbies, autonomy capacities and socialization, and school practices; the other for behavioral and emotional problems, which can be assessed as "normal", "borderline", or "clinical" on eight specific syndrome scales. The syndrome scales relating to the various psychopathological pictures are as follows: anxiety/depression, withdrawal, somatization, social problems, thought-related problems, attention problems, aggressive, and rule-breaking behavior. The problems are grouped into: internalizing problems (anxiety, depression, withdrawal, and somatization); externalizing problems (aggressive and rule-breaking behavior); and other problems (social, thought-related, and attention problems).

The revised version of the SCL-90-R ${ }^{34}$ is a 90 -item selfreport questionnaire for assessing psychopathological traits. This instrument sheds light on a broad range of psychological issues and psychopathological symptoms. The instrument is also useful for measuring patients' progress or treatment outcomes. The various items assess nine symptom dimensions: somatization, obsessive-compulsive, interpersonal sensitivity, depression, anxiety, hostility, phobic anxiety, paranoid ideation, and psychoticism.

The $\mathrm{CDI}^{35}$ consists of 27 items assessing feelings, behavior, and thoughts associated with depression in childhood and adolescence. Respondents choose one of three sentences that best describe how they have felt in the previous 2 weeks. Each answer is graded from 1 to 3, and the sum of the scores is calculated to obtain the total score (19 is the cut-off over which is determinable the presence of depressive traits). The Italian version of the CDI was used in this study. ${ }^{36,37}$

The BIS- $11^{38}$ is a widely used measure of impulsiveness. It includes 30 items that are scored to yield six first-order factors (attention, motor, self-control, cognitive complexity, perseverance, and cognitive instability), and three secondorder factors (attentional, motor, and nonplanning impulsiveness). We focused on the latter three subscales, which were combined to obtain a total score: the higher the score, the greater the level of impulsiveness identified. ${ }^{39}$ We used the Italian version of the BIS-11 for adolescents. ${ }^{40}$
The TAS- $20^{41}$ is a self-report questionnaire that measures the three factors defining alexithymia: "difficulty in identifying feelings", "difficulty in communicating feelings to others", and "externally oriented thinking". Respondents were classified as nonalexithymic (scores $<51$ ), borderline (scores 51-60), or alexithymic (scores $>61$ ). We used the Italian validated version of the TAS-20.42

\section{Data analysis}

Descriptive statistics were obtained for the scores emerging from the various tests, calculating the means, medians, standard deviations, and first and third quartiles. Frequency statistics were calculated for the categorical variables relating to the characteristics of the population under study. Given the uneven number of individuals comprising the samples considered, the scores were compared with the Mann-Whitney nonparametric rank sum test. The $\chi^{2}$ test was used to assess the association between habitual self-injury and presentation to our service for NSSI. Reference was made to generalized linear models with a mixed design for repeated measures, characterized by within and between variables, to assess the association between externalizing problems and total problems in the YSR and CBCL scores and the frequency of the NSSI. All statistical tests were two-way, and the threshold for significance was set at $P<0.05$. The data analysis was conducted with the SPSS (Statistical Package for Social Science, IBM ${ }^{\circledR}$ SPSS $^{\circledR}$ Statistics 22.0 for Windows; IBM Corp., Armonk, NY, USA).

The following scales were considered for statistical purposes: social competences, internalizing problems, total problems, and social problems in the YSR and CBCL questionnaires; interpersonal sensitivity, hostility, and total score in the SCL-90; total score in the CDI; attentional impulsiveness, motor impulsiveness, nonplanning impulsiveness, and total score in the BIS-11; and difficulty identifying feelings, difficulty describing feelings, externally oriented thinking, and total score in the TAS-20.

\section{Results \\ Differences between cases and controls}

According to the hypothesis, we expected clinical subjects to present worse psychopathological symptoms when compared to control cases. Results are reported in Table 3.

In fact, when the NSSI group was compared with the control group, self-injurers reported significantly higher scores in all the subscales considered:

\section{YSR}

1. Social competences $(Z=-2.335, P<0.05)$,

2. Internalizing problems $(Z=-4.823, P<0.05)$, 
Table 3 Scores in questionnaires for self-injurers and controls: mean (standard deviation)

\begin{tabular}{|c|c|c|}
\hline & Cases $(n=33)$ & Controls $(n=79)$ \\
\hline \multicolumn{3}{|l|}{ YSR subscales } \\
\hline Social competences & $39.55(9.93)$ & $44.26(9.07)$ \\
\hline Internalizing problems & $68.55(9.97)$ & $57.15(9.48)$ \\
\hline Externalizing problems & $60.13(9.33)$ & $50.37(9.11)$ \\
\hline Total problems & $65.97(8.17)$ & $53.58(9.05)$ \\
\hline Social problems & $63.19(8.30)$ & $57.59(7.24)$ \\
\hline \multicolumn{3}{|l|}{ CBCL subscales } \\
\hline Social competences & $38.17(7.92)$ & $45.27(7.44)$ \\
\hline Internalizing problems & $69.75(7.05)$ & $51.05(8.80)$ \\
\hline Externalizing problems & $65.67(6.55)$ & $47.03(8.56)$ \\
\hline Total problems & $69.13(4.12)$ & $47.76(9.08)$ \\
\hline Social problems & $64.67(7.15)$ & $53.05(4.65)$ \\
\hline \multicolumn{3}{|l|}{ SCL-90 subscales } \\
\hline Interpersonal sensitivity & $1.53(0.62)$ & $0.96(0.70)$ \\
\hline Hostility & $1.37(0.83)$ & $0.6 \mathrm{I}(0.6 \mathrm{I})$ \\
\hline Total score & $\mathrm{I} .44(0.5 \mathrm{I})$ & $0.80(0.79)$ \\
\hline CDI total & $22.15(9.62)$ & $12.5(6.75)$ \\
\hline \multicolumn{3}{|l|}{ BIS-II subscales } \\
\hline Attentional impulsiveness & I8.52 (4.74) & $16.28(3.52)$ \\
\hline Motor impulsiveness & $23.71(4.62)$ & $20.53(3.73)$ \\
\hline Nonplanning impulsiveness & $30.00(5.26)$ & $26.8 I(4.1 I)$ \\
\hline Total score & 72.24 (12.02) & $63.68(8.98)$ \\
\hline \multicolumn{3}{|l|}{ TAS- 20 subscales } \\
\hline Difficulty identifying feelings & $22.77(5.59)$ & $17.43(6.37)$ \\
\hline Difficulty describing feelings & $17.88(3.88)$ & $13.87(4.45)$ \\
\hline Externally oriented thinking & $24.04(4.19)$ & $20.22(3.84)$ \\
\hline Total score & $64.69(8.30)$ & $51.70(10.69)$ \\
\hline
\end{tabular}

Abbreviations: YSR, Youth Self-Report; $\mathrm{CBCL}$, Child Behavior Checklist; SCL-90, Symptom Checklist-90; CDI, Children's Depression Inventory; BIS-I I, Barratt's Impulsiveness Scale; TAS-20, Toronto Alexithymia Scale.

3. Externalizing problems $(Z=-4.570, P<0.05)$,

4. Total problems $(Z=-5.546, P<0.05)$, and

5. Social problems $(Z=-3.278, P<0.05)$.

\section{$\mathrm{CBCL}$}

1. Social competences $(Z=-3.274, P<0.05)$,

2. Internalizing problems $(Z=-6.402, P<0.05)$,

3. Externalizing problems $(Z=-6.421, P<0.05)$,

4. Total problems $(Z=-6.922, P<0.05)$, and

5. Social problems $(Z=-5.869, P<0.05)$.

\section{SCL-90}

1. Interpersonal sensitivity $(Z=-3.534, P<0.05)$,

2. Hostility $(Z=-4.314, P<0.05)$, and

3. Total score $(Z=-4.637, P<0.05)$.

\section{CDI}

1. Total score $(Z=-4.637, P<0.05)$.

\section{BIS-I I}

1. Attentional impulsiveness $(Z=-2.411, P<0.05)$,
2. Motor impulsiveness $(Z=-3.537, P<0.05)$,

3. Nonplanning impulsiveness $(Z=-2.492, P<0.05)$, and

4. Total score $(Z=-3.219, P<0.05)$.

\section{TAS-20}

1. Difficulty identifying feelings $(Z=-3.650, P<0.05)$,

2. Difficulty describing feelings ( $Z=-3.923, P<0.05)$,

3. Externally oriented thinking $(Z=-3.729, P<0.05)$, and

4. Total score $(Z=-5.037, P<0.05)$.

All NSSI cases had a total score above the threshold for borderline or clinical alexithymia: $73.1 \%$ of them were above the clinical cut-off (total score $\geq 61$ ), and the other $26.9 \%$ ranged between borderline cut-off (total score $\geq 51$ ) and the clinical cut-off.

\section{Differences according to the reasons for presenting to the clinical service, psychodiagnostic categories, and comparison between occasional and habitual self-injurers}

After the analysis based on cases-controls comparison, we performed a study about characteristics upon which we had divided the sample: reason for accessing our service, ICD-10 diagnosis, and frequency of self-injury episodes.

Patients who came to our clinical service for reasons other than NSSI scored higher on the externalizing problems scale $(Z=-3.021, P<0.05)$, and total problems scale $(Z=-2.129$, $P<0.05$ ) of the CBCL (Table 4). Analyzing diagnosis by ICD-10 versus dimensional categories, we found coherent results: a diagnosis of behavior and/or personality disorder coincided with a higher score on the externalizing problems scale of the CBCL $(Z=-2.450, P<0.05)$, while patients with affective and/or emotional disorders had a higher total score in the SCL-90 $(Z=-2.062, P<0.05)$, more depressive symptoms (CDI total score, $Z=-3.581, P<0.05$ ), and higher BIS-11 scores for nonplanning impulsiveness $(Z=-2.084$, $P<0.05$; Table 4).

A $\chi^{2}$ test was then run to test the assumption that habitual self-injurers (with $\geq 5$ episodes a year) come to the clinical service more frequently than occasional self-injurers, and the results confirmed this difference (Pearson's $\chi^{2}$ test $\chi^{2}(d f=1)=6.945$; $P<0.05$ ). Again considering the frequency of the NSSI behavior, habitual self-injurers ( $\geq 5$ episodes a year) returned higher scores than occasional self-injurers on the nonplanning impulsiveness scale of the BIS-11 $(Z=-2.351, P<0.05)$, and on the total score in the TAS-20 ( $Z=-1.971, P<0.05)$, whereas occasional self-injurers scored higher on the YSR total problems scale $(Z=-2.136, P<0.05)$, as listed in Table 4. 
Table 4 Scores in questionnaires for self-injurers by clinical features: mean (SD)

\begin{tabular}{|c|c|c|c|c|c|c|}
\hline \multirow[t]{2}{*}{ Questionnaires } & \multicolumn{2}{|c|}{ Frequency of NSSI } & \multicolumn{2}{|c|}{$\begin{array}{l}\text { Reason for presenting } \\
\text { to clinical services }\end{array}$} & \multicolumn{2}{|l|}{ ICD-I 0 diagnosis } \\
\hline & $\begin{array}{l}\text { Occasional } \\
\text { NSSI }(n=13)\end{array}$ & $\begin{array}{l}\text { Habitual } \\
\text { NSSI }(n=20)\end{array}$ & $\begin{array}{l}\text { NSSI } \\
(n=17)\end{array}$ & $\begin{array}{l}\text { Others } \\
(n=16)\end{array}$ & $\begin{array}{l}\text { Emotional and/or } \\
\text { affective disorders } \\
(n=19)\end{array}$ & $\begin{array}{l}\text { Behavioral and/or } \\
\text { personality disorders } \\
(n=\mid 4)\end{array}$ \\
\hline \multicolumn{7}{|l|}{ YSR subscales } \\
\hline Social competences & $42.33(8.98)$ & $37.59(10.35)$ & $40.00(11.73)$ & $39.19(8.57)$ & $36.67(10.52)$ & $44.27(6.94)$ \\
\hline Internalizing problems & $71.92(9.72)$ & $66.42(9.77)$ & $71.69(7.64)$ & 66.75 (II.55) & $71.83(9.6 I)$ & $64.27(9.59)$ \\
\hline Externalizing problems & $63.50(11.08)$ & $58.00(7.60)$ & $56.92(7.95)$ & $62.31(10.36)$ & $59.61(9.08)$ & $60.36(10.83)$ \\
\hline Total problems & $69.92(6.50)$ & $63.47(8.28)$ & $66.62(6.02)$ & $65.81(10.09)$ & $68.11(7.12)$ & $63.00(9.62)$ \\
\hline Social problems & $64.75(6.93)$ & $62.32(9.10)$ & $65.08(7.57)$ & $62.13(9.12)$ & $64.61(8.79)$ & $61.55(7.87)$ \\
\hline \multicolumn{7}{|l|}{ CBCL subscales } \\
\hline Social competences & $39.00(8.10)$ & $37.57(8.04)$ & $39.60(7.63)$ & $37.14(8.24)$ & $38.00(7.45)$ & $38.44(9.06)$ \\
\hline Internalizing problems & $68.80(7.57)$ & $70.43(6.7 I)$ & $70.50(5.70)$ & $69.21(8.04)$ & $71.00(6.79)$ & $67.67(7.37)$ \\
\hline Externalizing problems & $67.50(4.65)$ & $64.36(7.52)$ & $61.02(5.98)$ & $69.00(4.74)$ & $63.73(5.43)$ & $68.89(7.29)$ \\
\hline Total problems & $69.50(1.08)$ & $68.86(5.39)$ & $66.80(4.61)$ & $70.79(2.86)$ & $68.53(4.6 I)$ & $70.11(7.29)$ \\
\hline Social problems & $65.30(7.09)$ & $64.21(7.43)$ & $63.1(7.52)$ & $65.79(6.94)$ & $64.07(7.8 \mathrm{I})$ & $65.67(6.22)$ \\
\hline \multicolumn{7}{|l|}{ SCL-90 subscales } \\
\hline Interpersonal sensitivity & $\mathrm{I} .50(0.47)$ & $\mathrm{I} .55(0.7 \mathrm{I})$ & $1.49(0.65)$ & $1.58(0.63)$ & $1.73(0.64)$ & I.3I (0.55) \\
\hline Hostility & $1.18(0.60)$ & $1.47(0.93)$ & $\mathrm{I} .12(0.8 \mathrm{I})$ & $1.59(0.8 \mathrm{I})$ & $1.49(0.83)$ & $1.23(0.83)$ \\
\hline Total score & $1.32(0.48)$ & $1.50(0.53)$ & $1.39(0.37)$ & $1.48(0.63)$ & $\mathrm{I} .64(0.5 \mathrm{I})$ & $1.22(0.43)$ \\
\hline CDI total & $21.00(10.33)$ & $22.88(9.43)$ & $23.09(5.24)$ & $21.47(12.02)$ & $28.67(7.09)$ & $15.00(6.89)$ \\
\hline \multicolumn{7}{|l|}{ BIS-II subscales } \\
\hline Attentional impulsiveness & $18.44(5.00)$ & I8.58 (4.78) & $17.67(5.45)$ & $19.17(4.26)$ & $20.00(4.7 I)$ & $17.18(4.56)$ \\
\hline Motor impulsiveness & $21.44(5.39)$ & $25.42(3.20)$ & $24.00(4.97)$ & $23.50(4.54)$ & $25.90(2.96)$ & $21.73(5.06)$ \\
\hline Nonplanning impulsiveness & $26.78(4.21)$ & $32.42(4.76)$ & $30.67(5.24)$ & $29.50(5.45)$ & $30.80(4.87)$ & $29.27(5.73)$ \\
\hline Total score & $66.67(12.96)$ & $76.42(9.79)$ & $72.34(12.84)$ & $72.17(11.95)$ & $76.70(8.43)$ & $68.18(13.67)$ \\
\hline \multicolumn{7}{|l|}{ TAS-20 subscales } \\
\hline Difficulty identifying feeling & $21.44(6.50)$ & $23.47(5.11)$ & $22.14(5.64)$ & $23.50(5.68)$ & $23.15(5.18)$ & $22.38(6.16)$ \\
\hline Difficulty describing feelings & $16.00(3.87)$ & $18.88(3.60)$ & $17.79(3.87)$ & $18.00(4.07)$ & $17.77(4.34)$ & $18(3.54)$ \\
\hline Externally oriented thinking & $23.22(3.93)$ & $24.47(4.38)$ & $26.64(4.60)$ & $23.33(3.73)$ & $24.69(3.33)$ & $23.38(4.96)$ \\
\hline Total score & $60.67(8.44)$ & $66.82(7.62)$ & $64.57(8.21)$ & $64.83(8.77)$ & $65.62(7.57)$ & $63.77(9.18)$ \\
\hline
\end{tabular}

Abbreviations: SD, standard deviation; NSSI, nonsuicidal self-injury; ICD-10, international classification of diseases-10; YSR, Youth Self-Report; CBCL, Child Behavior Checklist; SCL-90, Symptom Checklist-90; CDI, Children's Depression Inventory; BIS-I I, Barratt's Impulsiveness Scale; TAS-20, Toronto Alexithymia Scale.

\section{Differences between adolescent NSSI cases' and their parents' perceptions}

A generalized linear mixed model for repeated measures was used, considering the respondent (patient-YSR or parents-CBCL) as a within variable, and NSSI frequency (occasional versus habitual) as a between variable. We found a statistically significant difference in the scores on the externalizing problems scale for the within variable $\left(F_{1,22}=8.312\right.$, $P<0.05)$. No differences emerged when the internalizing problems or total problems scales were considered.

\section{Discussion}

We conducted this study expecting clinical subjects to present worse psychopathological symptoms when compared to controls, with particular interest toward alexithymia and impulsiveness. It follows the discussion about aims' related data presented earlier, after some considerations about demographic and clinical features describing the subjects involved in this study.

\section{Descriptive variables characterizing the sample}

The age of our clinical sample - mean 15 (range: 12-17) years - confirms that the onset of NSSI is generally around 14 years of age. ${ }^{6}$ The maximum age of 17 years was due to the nature of the service provided at our developmental neuropsychiatry unit, which is for the diagnosis, treatment, and rehabilitation of children and adolescents up until they turn 18 years.

Although this was not a population study, it is worth commenting on the prevalence of the NSSI phenomenon in the general adolescent population. Among the 87 students who answered our questionnaires for the purpose of establishing a control group, eight reported at least one episode of NSSI. This proportion ( $9.2 \%$ of the sample) is consistent with the latest data in the literature on the prevalence of this disorder. 3,6

Our clinical sample showed a marked difference in the prevalence of NSSI by sex, with a F:M ratio of $3: 1$. This 
confirms previous reports on the situation in Europe, ${ }^{10,15,43}$ whereas population studies conducted in Italy identified no significant sex-related differences. ${ }^{11}$ When Andover et al ${ }^{14}$ studied a clinical sample, they found a greater tendency for females to be involved in medically relevant NSSI. Laukkanen et $\mathrm{al}^{7}$ also identified a F:M ratio of 3:1 in the general population for self-injury inflicted on parts of the body other than the arms - and therefore potentially more dangerous. This might plausibly be the reason for the F:M ratio seen in our clinical sample, which is bound to comprise tendentially more severe cases of NSSI because our department provides a second-level service (there are other first-level, territorial psychiatry and psychology services available). Hawton et $\mathrm{al}^{5}$ estimated that only one out of eight NSSI adolescents in the population at large access hospital services for this disorder, and so it is reasonable to assume that patients coming the attention of our unit in Padua in 2014 represented only a small proportion of all adolescents selfinjurers in the area, and the sex distribution may therefore differ between the clinical population that we considered and the general population. ${ }^{5}$

\section{Psychopathology}

To identify any psychiatric disorders associated with NSSI, we used the YSR, CBCL, and SCL-90 tests, in an effort to investigate a broad array of psychiatric issues because there are reports of a variety of different concomitant clinical conditions in NSSI adolescents. ${ }^{14}$ In addition to the aforementioned questionnaires, we also considered the CDI to better characterize the depressive symptoms identified in numerous other studies on NSSI. ${ }^{14,18,19}$

Our nonparametric Mann-Whitney test identified a significant statistical difference between cases and controls on all the scales examined, confirming that NSSI is strongly associated with various psychopathological conditions that warrant specialist clinical intervention. ${ }^{7,6,45}$

When we analyzed the results of the SCL-90, we found a statistically significant difference in the parameters considered, ie, interpersonal sensitivity, hostility, and global score. We thus concluded that, in addition to a higher overall rate of psychiatric symptoms, NSSI adolescents have a greater difficulty with interpersonal relations, demonstrating sentiments of personal inadequacy and inferiority, and also aggressiveness and rage, in relation to others. This difficulty in their relations with others is also confirmed by their scores on the scales for social competence and social problems, as assessed with the YSR and CBCL: NSSI adolescents reported having difficult interpersonal relations, and their parents' observations confirmed as much.
Distorted interpersonal relationships have been described in numerous studies, particularly in the light of the social function of behavior: You et $\mathrm{al}^{46}$ identified adolescents' relational frailty as a factor of diminished resistance to negative behavioral influences of their peers, and Hawton et $\mathrm{al}^{5}$ mentioned interpersonal difficulties among the risk factors for the onset of NSSI. Brunner et $\mathrm{al}^{6}$ also found a higher prevalence of problems with social relations among NSSI cases than in controls.

As for the clinical implications, these findings on the association between NSSI and inadequate sociorelational competences suggest that intervention focusing on improving communication and social skills (using psychotherapeutic methods such as dialectic-behavioral therapy, for instance, which focuses on developing interpersonal competences) could prove beneficial in the adolescent NSSI setting.

Turning now to depression, our study confirmed previous reports in the literature of a strong association between NSSI and depression. Another recent work conducted using the CDI likewise showed a statistically significant difference between cases and controls. ${ }^{18}$

When our clinical sample was divided on the basis of the reasons for coming to our service, there was only a significant difference in the CBCL scores relating to the scales for externalizing problems and total problems - higher scores being obtained by the parents of adolescents seeking help for reasons other than NSSI. This finding might prompt two lines of thinking: on one hand, parents may be more aware of the symptoms of the concomitant disorders, such as severe anxiety or depression, or conduct disorders, than of the signs of NSSI; on the other hand, NSSI adolescents tend to hide this behavior from their parents (and usually succeed). This would confirm the outcome of previous work showing that only one in three parents are aware of their children's NSSI episodes. ${ }^{47}$ One study also reported that half of the young people affected do not reveal their problem to anybody ${ }^{48}$ and, if they do so, they prefer to confide in their peers rather than speak to members of their families. ${ }^{49}$

Concerning the frequency of the NSSI episodes, our occasional self-injurers obtained higher YSR scores than the habitual cases, with a significant difference on the scale for total problems. This finding seems to contradict the report by Brunner et $a l,{ }^{6}$ who found more severe psychopathological variables coinciding with a greater frequency of the NSSI episodes. It is important to add that Brunner et $\mathrm{al}^{6}$ examined a broad sample of adolescents by means of a population study, whereas we considered patients presenting to our developmental neuropsychiatry service. The proportion of self-injurers in the general population who turn to the medical 
services for help is limited..$^{5}$ Our unit sees more cases of habitual than of occasional self-injuring adolescents and it seems likely that our clinical sample of occasional NSSI cases does not fully represent the occasional self-injurers in the adolescent population at large. To be more specific, using the $\chi^{2}$ test, we found that the occasional self-injurers coming under our observation had more often than not initially come to our service for other types of problem, and this would explain their higher scores obtained in the YSR.

When we analyzed the clinical sample by ICD-10 diagnosis - affective/emotional disorders or personality/ conduct disorders - we found significantly higher global scores on the SCL-90 and CDI for NSSI cases with the former diagnoses. This result is attributable to the type of psychopathological comorbidity concerned: patients with mood disorders, neurotic disorders, or disorders of the emotional sphere will predictably score higher in tests assessing depressive symptoms (CDI), or including subscales that assess somatization, anxiety, depression, or phobic anxiety (SCL-90), that is, psychopathologies with an internalizing type of psychobehavioral expression.

On the other hand, patients diagnosed with behavioral and/or personality disorders consistently revealed higher scores on the scale for externalizing problems in the CBCL: this scale assesses the parents' perception of their child's behavior revealing loss of control, rage, hyperactivity, distractibility, antisocial, or aggressive behavior - situations characteristic of the conditions in the category of the behavioral disorders.

Finally, we analyzed the mixed-design generalized linear models for repeated measures, considering respondents (patients in the case of the YSR, and parents in the case of the CBCL) as within variables, and occasional or habitual NSSI as the between variable. We found a statistically significant difference for the "respondent" variable as concerns externalizing problems, with parents tending to report more severe externalizing problems than their offspring. Although some studies have found a weak consistency between YSR and CBCL scores on the scales for externalizing problems, ${ }^{50,51}$ our result may be due to the ego-syntonic nature of NSSI behavior. In fact, individuals take such action deliberately and, from the patients' point of view, it serves as a solution for coping with emotional problems that they have to face.

When we analyzed the total problems scale, on the other hand, higher scores in the YSR and the CBCL tended to coincide with the occasional self-injuring cases. Much the same considerations would apply here as in the previously discussed case of higher scores being obtained in the YSR by patients who were occasional self-injurers. Data concerning different perception of behavioral problems between parents and children arise also a clinical reflection about the importance of working with both parents and sons/daughters to accept the disease and to build a solid working alliance. ${ }^{52,53}$

\section{Alexithymia}

One of the main objectives of our study was to better investigate the role of alexithymia in the onset of NSSI. As previously stated, we expected clinical sample to show greater levels of alexithymia when compared with the control group.

An important finding in our clinical sample is that $100 \%$ of the TAS-20 questionnaires administered to our patients obtained total scores above 51, the cut-off for distinguishing between normality and borderline or clinical alexithymia. Among the controls, the proportion of individuals above this threshold was $41.8 \%$.

When the scores on the TAS-20 were analyzed, the nonparametric Mann-Whitney test showed a significant difference between cases and controls in all three subscales, and in the total score. This finding is consistent with previously published reports. ${ }^{24,27,54}$

Judging from these results, difficulties in identifying and communicating emotions seem to be characteristic of the psychological functioning of NSSI adolescents, confirming our initial hypothesis. Selby and Joiner ${ }^{55}$ suggested that one of the mechanisms behind NSSI is a difficulty in managing negative emotions, and our results would support their view, suggesting a correlation between psychological dysfunctioning in this area and self-injuring behavior.

When we analyzed the alexithymia construct in our clinical sample in relation to the frequency of their NSSI episodes, there was a significant association between higher TAS-20 total scores - and particularly F2 (difficulty communicating emotions to others) - and habitual self-injury. Adolescents who are repeatedly self-injurers would, therefore, have more difficulty in managing their own emotions, and especially in communicating them to others. This is a factor that makes it more difficult for such adolescents to interact with their social environment, thus limiting their capacity to ask others for help. No statistically significant differences concerning alexithymia emerged when we compared patients presenting to our service for NSSI and those coming to our attention for other clinical reasons who presented NSSI in a later moment, or when we considered their ICD-10 diagnoses. These findings can be explained by the fact that alexithymia is a psychological construct involved in numerous different clinical conditions. It has no 
specific, exclusive association with either affective and/or emotional disorders or behavioral and/or personality disorders in patients with self-injury episodes. It is an element that can, however, differentiate the clinical NSSI population from the general population..$^{55,56}$

\section{Impulsiveness}

Impulsiveness was assessed by administering the BIS-11 questionnaire. The comparison between the clinical and control groups revealed a significant difference in all the subscales of the questionnaire, as well as in the total scores, indicating that impulsiveness is one of the traits of the clinical population. This finding supports previous studies on the topic, ${ }^{18,28,29}$ in which self-report measures identified a significant difference between self-injuring adolescents and controls, confirming our initial hypothesis. Nevertheless, other investigations conducted using behavioral tests generated different results. ${ }^{28,29}$ It has been suggested that this inconsistency may be due to the sample recruitment processes used in the various studies, or to the heterogeneous nature of the reference populations. For the time being, however, we are unaware of any publications on impulsiveness and NSSI - in our local population (the Veneto region), or in Italian adolescents generally - with which to compare the data emerging from our research. Another plausible explanation could lie in the instruments used: a meta-analysis ${ }^{57}$ has demonstrated that the outcomes of self-report questionnaires and behavioral measures are not fully consistent when it comes to assessing impulsiveness. We might add that selfinjuring adolescents are only impulsive in certain situations of particular emotional stress, which are difficult to replicate in the context of a behavioral study. Be that as it may, what emerges clearly from our data is that our sample of NSSI adolescents saw themselves as more impulsive than their peers in the control group.

No statistically significant differences emerged from our comparison between patients coming to our service for NSSI as opposed to other reasons. On the other hand, there was a significant difference on the nonplanning impulsiveness scale between occasional and habitual self-injurers. Nonplanning impulsiveness can be defined as an inadequate ability to think ahead, and our finding may indicate that habitual self-injurers have more difficulty in assessing their actions, particularly as concerns their ability to reflect on the possible consequences of an action before they put it into practice. We found no differences on the scale of motor impulsiveness, defined as the tendency to take action without stopping to think. This would mean that repeated NSSI are not induced by habitual self-injurers' greater difficulty in controlling their impulses - a trait shared by all self-injurers (irrespective of the frequency of such actions) by comparison with the general population. So, motor impulsiveness would seem to be important in the onset of NSSI behavior rather than the frequency of the episodes.

Motor impulsiveness was the only significant parameter emerging from the comparison between the subgroups of the clinical sample divided by ICD-10 diagnosis: patients with affective and/or emotional disorders scored higher than patients diagnosed with behavioral and/or personality disorders. We can interpret this finding in the light of the demonstrated association between NSSI and impulsiveness, also bearing in mind that disorders of internalizing type are the most common psychiatric comorbidity associated with NSSI. As a consequence, adolescents with NSSI and a concomitant internalizing type of disorder have a tendency to reveal higher scores in this dimension of impulsiveness.

\section{Conclusion}

In general, we can say that, irrespective of its clinical characteristics, NSSI reveals associations with a variety of psychiatric conditions rather than presenting any specific link with a particular diagnostic category. NSSI can be seen as a disorder that spans the various categories of psychopathology examined in this study, justifying the increasing tendency to see NSSI as a separate pathological entity. Proof of this tendency lies in the recent adoption in the DSM-V of separate diagnostic criteria for NSSI, which is no longer relegated to the role of a symptom of borderline personality disorder. From a formal standpoint, this separation of NSSI from borderline personality disorder in the classification allows for the co-occurrence of NSSI with other psychiatric disorders - a situation that, judging from the results of this study, appears to be far from rare.

In particular, consistent with our hypothesis, alexithymia seems to be a relevant aspect in the onset of NSSI behavior, especially with reference to difficulties in identifying and communicating emotions. Besides reinforcing knowledge around NSSI's psychological correlates, this data could be particularly meaningful to clinician and therapists, in terms of treatment, to pay particular attention to improve emotional managing skills when working with self-injuring adolescents and their parents to build an efficacy working alliance. ${ }^{58-60}$

With regard to impulsiveness, it emerged as a trait shared by all self-injurers. A significant difference on the nonplanning impulsiveness scale between occasional and repetitive NSSI came out when considering the clinical population, 
while motor impulsiveness seems to be more important to the self-injuring onset. Given the discordance among studies, further investigations are needed about the NSSIimpulsiveness relationship.

Our study has some limitations that need to be acknowledged. First of all, there is the limited size of the clinical sample considered, which made it impossible for us to further divide our cases into subgroups (beyond those considered here) for statistical reasons. Another limitation concerns our exclusive use of self-reporting assessment tools. Although they have their advantages (they are quick and easy to administer, inexpensive, and obtain an abundance of information directly from the individual concerned), this type of assessment suffers from the risk of the responses being influenced by factors such as social desirability, subjective interpretation of the questions, and the respondent's influence ability, although the presence of an operator enabled errors due to an inappropriate interpretation of the question to be reduced, and our tests could be suspended and repeated if situations arose that might interfere with the questionnaires' adequate completion.

Albeit with these limitations, this study provides an important contribution on the topic of self-injury, given also that few reports in the literature have analyzed such a large number of variables. There has so far been a general paucity of research on alexithymia and impulsiveness in NSSI patients, and the number of studies on the Italian population, and in the area of the Veneto, is extremely limited.

\section{Disclosure}

The authors report no conflicts of interests in this work.

\section{References}

1. Nock MK. Self-injury. Annu Rev Clin Psychol. 2010;6:339-363.

2. American Psychiatric Association. Diagnostic and Statistical Manual of Mental Disorders (DSM-V). 5th ed. Arlington, VA: American Psychiatric Publishing; 2013.

3. Swannell SV, Martin GE, Page A, Hasking P, St John NJ. Prevalence of nonsuicidal self-injury in nonclinical samples: systematic review, meta-analysis and meta-regression. Suicide Life Threat Behav. 2014; 44(3):273-303.

4. Muehlenkamp JJ, Claes L, Havertape L, Plener PL. International prevalence of adolescent non-suicidal self-injury and deliberate self-harm. Child Adolesc Psychiatry Ment Health. 2012;6:10.

5. Hawton K, Saunders KE, O'Connor RC. Self-harm and suicide in adolescents. Lancet. 2012;379(9834):2373-2382.

6. Brunner R, Kaess M, Parzer P, et al. Life-time prevalence and psychosocial correlates of adolescent direct self-injurious behavior: a comparative study of findings in 11 European countries. J Child Psychol Psychiatry. 2014; 55(4):337-348.

7. Laukkanen E, Rissanen M, Tolmunen T, Kylmä J, Hintikka J. Adolescent self-cutting elsewhere than on the arms reveals more serious psychiatric symptoms. Eur Child Adolesc Psychiatry. 2013;22(8):501-510.

8. Claes L, Vandereycken W, Vertommen H. Self-injury in female versus male psychiatric patients: a comparison of characteristics, psychopathology and aggression regulation. Pers Individ Dif. 2007;42(4):611-621.
9. Kirkcaldy BD, Brown J, Siefen RG. Disruptive behavioural disorders, self harm and suicidal ideation among German adolescents in psychiatric care. Int J Adolesc Med Health. 2006;18(4):597-614.

10. Saçarçelik G, Türkcan A, Güveli H, Yesilbas D. The prevalence of deliberate self-harm behavior and its association with sociodemographic features in patients referred to secondary care psychiatric clinic for adolescents and young adults. Dusunen Adam. 2011;24(4):253-264.

11. Cerutti R, Manca M, Presaghi F, Gratz KL. Prevalence and clinical correlates of deliberate self-harm among a community sample of Italian adolescents. J Adolesc. 2011;34(2):337-347.

12. Manca M, Presaghi F, Cerutti R. Clinical specificity of acute versus chronic self-injury: measurement and evaluation of repetitive nonsuicidal self-injury. Psychiatry Res. 2014;215(1):111-119.

13. Di Pierro R, Sarno I, Perego S, Gallucci M, Madeddu F. Adolescent nonsuicidal self-injury: the effects of personality traits, family relationships and maltreatment on the presence and severity of behaviours. Eur Child Adolesc Psychiatry. 2012;21(9):511-520.

14. Nock MK, Joiner TE Jr, Gordon KH, Lloyd-Richardson E, Prinstein MJ. Non-suicidal self-injury among adolescents: diagnostic correlates and relation to suicide attempts. Psychiatry Res. 2006;144(1):65-72.

15. Brunner R, Parzer P, Haffner J, et al. Prevalence and psychological correlates of occasional and repetitive deliberate self-harm in adolescents. Arch Pediatr Adolesc Med. 2007;161(7):641-649.

16. Lloyd-Richardson EE, Perrine N, Dierker L, Kelley ML. Characteristics and functions of non-suicidal self-injury in a community sample of adolescents. Psychol Med. 2007;37(8):1183-1192.

17. Ross $\mathrm{S}$, Heath N. A study of the frequency of self-mutilation in a community sample of adolescents. J Youth Adolesc. 2002;31(1):67-77.

18. Rodav O, Levy S, Hamdan S. Clinical characteristics and functions of nonsuicide self-injury in youth. Eur Psychiatry. 2014;29(8):503-508.

19. Hintikka J, Tolmunen T, Rissanen M, Honkalampi K, Kylmä J, Laukkanen E. Mental disorders in self-cutting adolescents. $J$ Adolesc Health. 2009;44(5):464-467.

20. Kumar G, Pepe D, Steer RA. Adolescent psychiatric inpatients' selfreported reasons for cutting themselves. JNerv Ment Dis. 2004; 192(12): 830-836.

21. Claes L, Vandereycken W, Vertommen H. Eating-disordered patients with and without self-injurious behaviours: a comparison of psychopathological features. Eur Eat Disord Rev. 2003;11(5):379-396.

22. Solano R, Fernández-Aranda F, Aitken A, LópezC, Vallejo J. Self-injurious behaviour in people with eating disorders. Eur Eat Disord Rev. 2005; 13(1):3-10.

23. Nemiah JC, Freyberger H, Sifneos PE. Alexithymia: a view of the psychosomatic process. In: Hill OW, editor. Modern Trends in Psychosomatic Medicine. Vol 3. London, England: Butterworths; 1976: 430-439.

24. Paivio SC, McCulloch CR. Alexithymia as a mediator between childhood trauma and self-injurious behaviors. Child Abuse Negl. 2004; 28(3):339-354.

25. Zlotnick C, Shea MT, Pearlstein T, Simpson E, Costello E, Begin A. The relationship between dissociative symptoms, alexithymia, impulsivity, sexual abuse, and self-mutilation. Compr Psychiatry. 1996; 37(1):12-16.

26. Evren C, Evren B. Self-mutilation in substance-dependent patients and relationship with childhood abuse and neglect, alexithymia and temperament and character dimensions of personality. Drug Alcohol Depend. 2005;80(1):15-22.

27. Polk E, Liss M. Psychological characteristics of self-injurious behavior. Pers Individ Dif. 2007;43(3):567-577.

28. Glenn CR, Klonsky ED. A multimethod analysis of impulsivity in nonsuicidal self-injury. Personal Disord. 2010;1(1):67-75.

29. Janis IB, Nock MK. Are self-injurers impulsive? results from two behavioral laboratory studies. Psychiatry Res. 2009;169(3): 261-267.

30. Herpertz S, Sass H, Favazza A. Impulsivity in self-mutilative behavior: psychometric and biological findings. J Psychiatr Res. 1997;31(4): $451-465$. 
31. Manual for the ASEBA School-Age Forms \& Profiles; 2001. Achenbach, TM, Rescorla, LA. Burlington, VT: University of Vermont, Research Center for Children, Youth, and Families.

32. Ivanova MY, Achenbach TM, Rescorla LA, et al. The generalizability of the Youth Self-Report syndrome structure in 23 societies. J Consult Clin Psychol. 2007;75(5):729-738.

33. Frigerio A, Vanzin L, Pastore V, et al. The Italian preadolescent mental health project (PrISMA): rationale and methods. Int J Methods Psychiatr Res. 2006;15(1):22-35.

34. Derogatis LR. Symptom Checklist 90-R: Administration, Scoring, and Procedures Manual. 3rd ed. Minneapolis, MN: National Computer Systems; 1994.

35. Kovacs M. Children's Depression Inventory (CDI) manual. Toronto, ON: Multi-Health Systems; 1992.

36. Camuffo M, Cerutti R, Lucarelli L, Mayer R. Il CDI (Children's Depression Inventory) nella scuola media: indagine psicometrica. Bollettino di Psicologia Applicata. 1988a;185:37-46. Italian.

37. Camuffo M, Cerutti R, Lucarelli L, Mayer R. Children's depression inventory: Italian version. Firenze, Italy: Organizzazioni Speciali; 1988 b.

38. Patton JH, Stanford MS, Barratt ES. Factor structure of the Barratt impulsiveness scale. J Clin Psychol. 1995;51(6):768-774.

39. Stanford MS, Mathias CW, Dougherty DM, Lake SL, Anderson NE, Patton JH. Fifty years of the Barratt Impulsiveness Scale: an update and review. Pers Individ Dif. 2009;47(5):385-395.

40. Fossati A, Barratt ES, Acquarini E, Di Ceglie A. Psychometric properties of an adolescent version of the Barratt Impulsiveness Scale-11 for a sample of Italian high school students. Percept Mot Skills. 2002; 95(2):621-635.

41. Rieffe C, Oosterveld P, Terwogt MM. An alexithymia questionnaire for children: factorial and concurrent validation results. Pers Individ Dif. 2006;40(1):123-133.

42. Bressi C, Taylor G, Parker J, et al. Cross validation of the factor structure of the 20-item Toronto Alexithymia Scale: an Italian multicenter study. J Psychosom Res. 1996;41(6):551-559.

43. Madge N, Hewitt A, Hawton K, et al. Deliberate self-harm within an international community sample of young people: comparative findings from the child \& adolescent self-harm in Europe (CASE) study. J Child Psychol Psychiatry. 2008;49(6):667-677.

44. Andover MS, Gibb BE. Non-suicidal self-injury, attempted suicide, and suicidal intent among psychiatric inpatients. Psychiatry Res. 2010; 178(1):101-105.

45. Baetens I, Claes L, Muehlenkamp J, Grietens H, Onghena P. Differences in psychological symptoms and self-competencies in non-suicidal self-injurious Flemish adolescents. J Adolesc. 2012;35(3):753-759.

46. You J, Lin MP, Fu K, Leung F. The best friend and friendship group influence on adolescent nonsuicidal self-injury. J Abnorm Child Psychol. 2013;41(6):993-1004.
47. Baetens I, Claes L, Onghena P, et al. Non-suicidal self-injury in adolescence: a longitudinal study of the relationship between NSSI, psychological distress and perceived parenting. J Adolesc. 2014;37(6): $817-826$.

48. Baetens I, Claes L, Muehlenkamp J, Grietens H, Onghena P. Nonsuicidal and suicidal self-injurious behavior among Flemish adolescents: a web-survey. Arch Suicide Res. 2011;15(1):56-67.

49. Evans E, Hawton K, Rodham K. In what ways are adolescents who engage in self-harm or experience thoughts of self-harm different in terms of help-seeking, communication and coping strategies? J Adolesc. 2005;28(4):573-587.

50. Salbach-Andrae H, Lenz K, Lehmkuhl U. Patterns of agreement among parent, teacher and youth ratings in a referred sample. Eur Psychiatry. 2009;24(5):345-351.

51. Rescorla LA, Ginzburg S, Achenbach TM, et al. Cross-informant agreement between parent-reported and adolescent self-reported problems in 25 societies. J Clin Child Adolesc Psychol. 2013;42(2):262-273.

52. Gatta M, Spoto A, Svanellini L, et al. Alliance with patient and collaboration with parents throughout the psychotherapeutic process with children and adolescents: a pilot study. Journal of Psychopathology. 2012;18:28-34.

53. Gatta M, Ramaglioni E, Lai J, et al. Psychological and behavioral disease during developmental age: the importance of the alliance with parents. Neuropsychiatr Dis Treat. 2009;5:541-546.

54. Cerutti R, Calabrese M, Valastro C. Alexithymia and personality disorders in the adolescent non-suicidal self injury: preliminary results. Soc Behav Sci. 2014;114:372-376.

55. Selby EA, Joiner TE Jr. Cascades of emotion: The emergence of borderline personality disorder from emotional and behavioral dysregulation. Rev Gen Psychol. 2009;13(3):219-229.

56. Gatta M, Balottin L, Mannarini S, et al. Familial factors relating to alexithymic traits in adolescents with psychiatric disorders. Clinical Psychologist. Epub 2016.

57. Cyders MA, Coskunpinar A. Measurement of constructs using selfreport and behavioral lab tasks: is there overlap in nomothetic span and construct representation for impulsivity? Clin Psychol Rev. 2011;31(6): 965-982.

58. Gatta M, Zotto L, Nequinio G, et al. Parents of adolescents with mental disorders: improving their caregiving experience. J Child Fam Stud. 2011;20:478-490.

59. Gatta M, Dal Zotto L, Del Col L, et al. Analytical psychodrama with adolescents suffering from psycho-behavioral disorder: Short-term effects on psychiatric symptoms. Arts Psychother. 2010;37(3):240-247.

60. Gatta M, Gallo C, Vianello M. Art therapy groups for adolescents with personality disorders. Arts Psychother. 2014;41:1-6.
Neuropsychiatric Disease and Treatment

\section{Publish your work in this journal}

Neuropsychiatric Disease and Treatment is an international, peerreviewed journal of clinical therapeutics and pharmacology focusing on concise rapid reporting of clinical or pre-clinical studies on a range of neuropsychiatric and neurological disorders. This journa is indexed on PubMed Central, the 'PsycINFO' database and CAS,

\section{Dovepress}

and is the official journal of The International Neuropsychiatric Association (INA). The manuscript management system is completely online and includes a very quick and fair peer-review system, which is all easy to use. Visit http://www.dovepress.com/testimonials.php to read real quotes from published authors. 